\title{
O autor invisível: discutindo a questão do autor nas distopias literárias
}

\section{Carolina Figueiredo}

\section{Resumo:}

A tradição literária e mesmo questões mais modernas relativas à produção intelectual dão ênfase total à figura do autor. Dentro das visões correntes o autor seria basicamente um indivíduo produtor de idéias e/ou manifestações artísticas que se referem à sua trajetória e à sua subjetividade. $\mathrm{O}$ autor seria assim entendido como sujeito uno, produtor de manifestações peculiares que dependem dele, e exclusivamente dele para existirem. A noção de autor acaba perdendo um pouco de sua força com o desenvolvimento da psicologia no século XX e posteriormente com a criação da Análise de Discurso, que coloca o autor como sujeito influenciado pelo contexto histórico e pelo discurso do outro.

\section{Palavras Chave:}

autor, outro, análise do discurso.

\begin{abstract}
:
The literary tradition and even more modern questions related to the intellectual production give total emphasis to the author figure. In the current visions the author would be basically an individual who produces ideas and/ or artistic manifestations which refer to his own trajectory and subjectivity. The author would be understood as one subject, producer of specific manifestations which depend exclusively on him to exist. The notion of author looses a little of its strength with the XX century's Psychology development and after that with the creation of the Discourse Analyses, which puts the author as influenced by the historical context and the discourse of the Other.
\end{abstract}

\section{Keywords:}

author, other, discourse analysis.

\section{A questão do autor}

A tradição literária e mesmo questões mais modernas relativas à produção intelectual dão ênfase total à figura do autor. Dentro das visões mais convencionais o autor seria basicamente um sujeito produtor de idéias e/ou manifestações artísticas que se referem à sua trajetória e à sua subjetividade. $\mathrm{O}$ autor seria assim entendido como sujeito uno, produtor de manifestações peculiares que dependem dele, e exclusivamente dele para existirem. Foucault sintetiza esta noção "romântica" de autor afirmando simplesmente que: "O autor é sem dúvida aquele a quem se pode atribuir o que foi dito ou escrito" (FOUCAULT, 1969: 265). Para ele, "essa noção do autor constitui o momento crucial da individualização na história das idéias, dos conhecimentos, das literaturas, e também na história da filosofia e das ciências" (FOUCAULT, 1969: 267).

A noção "romântica" de autor uno, contudo, acaba perdendo um pouco de sua força com o desenvolvimento da psicologia no século XX. Com a descoberta do inconsciente por Freud revela-se a fragilidade do sujeito consciente e a pluralidade de elementos que os indivíduos têm ocultos em si. Além disso, as descobertas freudianas apontam para a existência do sujeito fora do sujeito individual por meio do Superego. Jung estende esta visão tratando dos arquétipos, conteúdos simbólicos ancestrais da humanidade que estão presentes em estágios pré-conscientes ou mesmo inconscientes em todos nós e que podem ser revelados por meio da 
literatura e de outras manifestações culturais ainda que não sejam identificados de modo consciente.

O Ego então não tem domínio total sobre as questões que acercam o indivíduo e que dele emanam. Desse modo, a consciência aparece apenas como síntese, unidade das impressões sensíveis e dos atos e aspirações do sujeito (CASTORIADIS, 2000: 84). Refletindo sobre as noções de consciente, inconsciente e superego, temos então que além do sujeito existe alguém que fala por ele ou com ele, seja este alguém exterior ou uma parcela insuspeita de sua psique. Assim, o sujeito é permeado por dois discursos, que não emanam propriamente do Ego, mas que nele encontram suporte para sua enunciação: o discurso do Outro psicanalítico, que compõe o inconsciente dos sujeitos, ou seja, é um enunciado "próprio" no sentido em que emana dos indivíduos, mas sobre o qual não é possível exercer nenhum tipo de controle. E o discurso do outro social. Este é exterior aos sujeitos, pois pertence ao grupo social e ao contexto histórico onde os sujeitos se inserem. A síntese que a consciência realiza acaba por equacionar estes dois "outros" no discurso que é, ou está "em mim" abrigado. Ao tratar do Outro psicanalítico, Castoriadis (2000: 84) comenta que: "o discurso do Outro está em mim e me domina", na medida em que compõe o imaginário dos sujeitos, levado à tona (ao Ego) por meio de manifestações artísticas, racionalizações, argumentações, etc. É neste sentido que os indivíduos são dominados por um "imaginário vivido" e que define a realidade.

Desse modo a alienação dos sujeitos passa pelo desconhecimento do inconsciente e do domínio que este exerce - segundo a proposição de Castoriadis - por meio do imaginário. Não é possível fugir das proposições do inconsciente uma vez que a) estas afloram muitas vezes de modo igualmente inconsciente, ou seja, não se pode controlar quando e como aparecem; e, b) não é possível extirpar o inconsciente dos sujeitos uma vez que ele é parte da sua própria constituição. Assim, todos estamos submetidos a esta alienação primordial de nós mesmos. O outro social não está dentro dos sujeitos, mas lhes é igualmente natural, pois estamos todos imersos em coletividades onde diferentes ideologias, falares e pensamentos se entrecruzam, sendo apropriados pelos sujeitos no próprio fazer social. Os discursos que permeiam os sujeitos seriam assim historicamente contingenciados, o que faz com que o autor ocupe uma posição histórica "tanto no sentido de que não se caracteriza a partir de uma personalidade quanto no sentido de que ela se modifica em decorrência das alterações e diversificações das modalidades enunciativas" (POSSENTI, 1995). Possenti articula a relação entre historicidade e discurso do outro da seguinte forma:

Mesmo nos casos em que não poderá detectar formalmente a presença do outro [...] sempre poderá dizer que há pelo menos uma presença constitutiva do outro - dado que a tese que compõe o núcleo duro dessa teoria é que todos os componentes de um discurso são históricos, que seu exterior é densamente povoado por outros discursos e, portanto, sua emergência num determinado texto numa determinada instância nunca é original, mas já antecedida de muitas ocorrências. Portanto, o discurso nunca é originário de um eu, mas de um outro (discurso). Em termos de análise, no entanto, parece que o interessante é a depreensão dos critérios pelos quais se pode dizer que há uma presença de outro, já que a afirmação de sua presença tem papel axiomático neste modo de ver as coisas (POSSENTI, 1995).

Trata-se então de perceber como a voz discursiva de A se faz notar em B, ou seja, de perceber a heterogeneidade dos discursos, uma vez que os falares de um sujeito são compostos pelos falares de outros, sejam estes quais forem. Desse modo, a atividade do autor não seria apenas historicamente determinada, mas seria também, de certo modo, coletiva na medida em que o autor em sua obra utiliza as falas de outrem que o permeia. A ação narrativa é na verdade um fluxo histórico, composto pelos discursos que o autor apreende no curso da vida e mais especificamente ao denominar-se autor, ocupando assim uma espécie de lugar privilegiado para falar - e neste falar reproduzir - sobre a sociedade que o circunda.

Assim como no caso do Outro psicanalítico os sujeitos estão alienados sobre este processo, o que não os impede, contudo de buscar uma espécie de autonomia do discurso do outro, baseada no reconhecimento de 
que este outro existe. A autonomia depende então da capacidade individual de se negar o discurso do outro, tarefa cumprida sempre apenas parcialmente, pois uma vez que em mim introjetado tal discurso passa a ser também meu e mesmo o discurso da negação do outro é tomado de outros sujeitos.

\section{O outro e a autoria}

Tanto o Outro quanto o autor ocupam lugares de fala historicamente determinados; o que nos leva a célebre questão de Foucault: "por que um discurso surge em um lugar e não em outro?” (FOUCAULT, 1969: 264). Ou seja, como um discurso aparece de forma singular em determinado momento histórico, enunciado por um sujeito específico e não em outro momento ou outro sujeito? Em detrimento do autor ser perpassado por enunciados "disponíveis" na sociedade ele se torna - e por isso o denominamos autor - portador de um discurso inédito seja na sua forma ou no seu conteúdo. Além desta, outras questões são apresentadas por este pensador, como: «"o que é uma obra e de que elementos ela se compõe?" e "se o indivíduo não fosse um autor, será que se poderia dizer que o que ele escreveu (...) poderia ser chamado de 'obra'?"’. Destas decorre ainda uma outra questão relevante: "suponhamos que se trate de um autor: será que tudo o que ele escreveu ou disse faz parte da sua obra?" (FOUCAULT, 1969: 269). Tem-se então que tanto autor quanto obra são conceitos multifacetados e complexos, possuindo o próprio nome de "autor" uma conceituação problemática. Para solucionar esta questão, Foucault (1) cria a noção de função autor, de onde se apreende que o autor é apenas “(...) o princípio de uma certa unidade de escrita” (FOUCAULT, 1969: 278), tal unidade seria dada pela operação do Ego do autor sobre a realidade que lhe é exterior (2), realizando uma espécie de síntese entre tal realidade e os conteúdos imaginários, dos quais nos fala Castoriadis, ou seja, organizando por meio do Ego as relações entre o Outro e o outro.

Vinculado às condições históricas e do seu inconsciente temos que nenhum autor tem controle total sobre o seu discurso. Parte-se de determinada intencionalidade, e nesse ponto não se pode negar que questões subjetivas se atrelam à enunciação. Temos então um ponto em comum entre a visão romântica de autor e a visão deste como enunciador de discursos singulares: a subjetividade. Porém esta subjetividade não é demarcada apenas pelo Ego consciente de si e do mundo, criador, como propõe a visão romântica, mas do Outro psicanalítico, que imprime aos enunciados que lhe são exteriores, ou seja, dos outros, marcas próprias que indicam a imaginação do autor e a singularidade de suas construções (ainda que historicamente contingenciadas). Estas marcas do Outro sobre o enunciado poderiam, dentro de determinados parâmetros, serem apresentadas como indícios de autoria. Em outras palavras, e complexificando ainda mais este raciocínio, temos que a autoria não existe em função do discurso do autor ("meu" discurso), mas sim daquilo que não pode ser imediatamente identificado como discurso do outro.

Para Foucault a noção de autor só existe em função de sua obra. Ou seja, o autor é constituído a partir do conjunto de textos por ele forjados em função de determinados aspectos tais como responsabilidade e projeto sobre a sua obra. Assim o autor não seria exatamente nem o proprietário nem o responsável por seus textos (FOUCAULT, 1969:265). Temos assim que o autor é uma construção discursiva, diferenciada do escritor.

Um nome de autor não é simplesmente um elemento em um discurso (...); ele exerce um certo papel em relação ao discurso: assegura uma função classificatória; tal nome permite reagrupar um certo número de textos, delimita-los, deles excluir alguns, opô-lo a outros (...). O fato de que vários textos tenham sido colocados sob um mesmo nome indica que se estabelece entre eles uma relação de homogeneidade ou de filiação, ou de autenticação de uns pelos outros, ou de explicação recíproca, ou de utilização concomitante. Enfim, o nome do autor caracteriza um certo modo de ser do discurso (FOUCAULT, 1969: 273).

Foucault considera o «verdadeiro autor» como fundador de discursividades e por imprimir parâmetros para a produção de outros textos. Daí decorre que "as verdadeiras marcas de autoria são da ordem do discurso" 
(POSSENTI, 2002). Desta decorre ainda uma definição de autor na qual este deve ser considerado "não como a projeção literal e mais ou menos racionalizada de um sujeito portador e instaurador de sentido, mas como um nó em uma rede" (POSSENTI, 2002). Assim, deixa-se de lado a visão dos sujeitos enquanto indivíduos, senhores de suas ações e inaugura a idéia de «dispersão do sujeito». A dispersão trata não do sujeito uno mas do sujeito perpassado pelo discurso do Outro, ou dos outros. Esta noção está relacionada ainda a uma outra questão foucaultiana: a de heterogeneidade discursiva, já que esta pressupõe o local de fala dos indivíduos. O ponto primordial de ambos os conceitos é perceber que o sujeito "fala ao mesmo tempo que é falado", isto é dito pelo que os outros dizem, o autor ocupa lugares discursivos meramente provisórios sendo ao mesmo tempo produtor e reprodutor do discurso a que dá passagem. Para Fischer:

A pergunta “quem fala?" desdobra-se em muitas outras: qual o status do enunciador? Qual a sua competência? Em que campo de saber se insere? Qual seu lugar institucional? Como seu papel se constitui juridicamente? Como se relaciona hierarquicamente com outros poderes além do seu? (FISCHER, 2001).

O sujeito não é dono da sua história, mas faz parte de seu fluxo, estando suscetível a ela. O autor então é, dentro da perspectiva foucaultiana, organizador de discursos. O discurso não é, contudo, autônomo, se não o autor seria mero reprodutor, mas é condicionado pelo sujeito histórico e pelo sujeito indivíduo (ou, em outros termos o sujeito psicológico).

O discurso, assim concebido, não é a manifestação, majestosamente desenvolvida, de um sujeito que pensa, que conhece, e que o diz: é, ao contrário, um conjunto em que podem ser determinadas a dispersão do sujeito e sua descontinuidade em relação a si mesmo. É um espaço de exterioridade em que se desenvolve uma rede de lugares distintos. (FOUCAULT, 1986: 61-62). )

O outro social está no indivíduo, mas não é o indivíduo. Embora o autor não tenha poder total sobre seu discurso o outro também não o tem. A autoria é síntese, nascida da relação dialética entre o "eu" e o outro sendo, portanto, polifônica. Esta noção nasce ainda em Marx, que destrona o sujeito diante do processo histórico. Althusser afirma que Marx e Freud se aproximariam um do outro por meio do materialismo e da dialética (ALTHUSSER, 2000: 78). Esta constatação se baseia em dois pressupostos fundamentais. O primeiro é que a tese mínima do materialismo é a existência da realidade fora do pensamento ou da consciência, neste sentido Freud seria materialista, pois nega a primazia da consciência (ALTHUSSER, 2000: 77), o segundo é a questão social, presente em Freud por meio do superego e presente em toda a obra de Marx (3) que destrona o sujeito em função do coletivo. Laclau corrobora com esta visão ao afirmar que o discurso é uma instância limítrofe com o social, pois cada ato social tem um significado, e é constituído na forma de seqüências discursivas que articulam elementos lingüísticos e extralingüísticos (LACLAU apud FISCHER, 2001: 137).

\section{O autor invisível}

Vimos acima que Foucault considera como autor aquele indivíduo que é capaz de organizar discursos em comum. Assim, a unidade dos discursos é apenas aparente, pois no seu interior está o sujeito disperso e descontínuo que realiza uma espécie de bricolagem com o discurso do Outro. Tal aparência de unidade esconde ainda outra questão: a relação dual entre o sujeito e o Outro. Se o indivíduo fala ao mesmo tempo que é falado temos que considerar que esta sua fala inclui algum componente de subjetividade. Do mesmo modo, se na visão foucaltiana o discurso atesta a dispersão do sujeito, há então um sujeito a ser disperso. A visão do sujeito assujeitado nega que além das forças sociais que o perpassam existe uma psique. Se, como Althusser propõe, os indivíduos ocupam lugares sociais desde o seu nascimento, e isto é necessário para que se exerça determinado papel, e se, como Freud propõe, o Ego é forjado, em grande parte, da relação com o Outro (4), temos que existe notavelmente uma externalidade que determinará o acervo de discursos dos sujeitos. Porém 
a escolha de um discurso em detrimento de outro depende de fatores subjetivos. Para Furlanetto:

$\mathrm{Na}$ ótica da psicanálise de Lacan, em que Pêcheux se inspira, o sujeito 'não pertence ao registro dos dados, não é um dado. [...] O sujeito não é um dado, mas uma descontinuidade nos dados' (MILLER, 1997: 253). Isso corresponde a dizer que 'sujeito' não equivale a pessoa nem a indivíduo. Miller diz que o sujeito aparece como uma caixa vazia, onde podem ser inscritas as variações da posição subjetiva (FURLANETTO, 2003: 238). ).

Contudo, para Pêcheux mesmo a noção de subjetividade é imaginária (PECHEUX, 1988). O autor tenta solucionar esta questão buscando o conceito de forma-sujeito em Althusser. A forma sujeito seria o sujeito histórico das formações discursivas, regulador do que pode ser dito em determinado momento. Assim formação discursiva e forma-sujeito seriam coerentes entre si, sendo o sujeito do discurso também o Sujeito da formação discursiva. Desse modo a forma-sujeito conjuga o que é prévio ao indivíduo (fundamentado na historicidade) e aquilo que ele articula na enunciação. Desta premissa decorrem diferentes posicionamentos em relação à enunciação: superposição e contra-identificação. Na superposição, o sujeito se identifica com a forma-sujeito. "Ele 'consente' na reduplicação: este é o bom sujeito, aquele que respeita as regras do espaço de onde fala" (FURLANETTO, 2003).

Temos então que os fatores subjetivos são determinantes no processo de enunciação, em grande parte, justamente porque o sujeito não os controla, já que as motivações e desejos pertencem ao campo do inconsciente. Ao escolher um discurso e não outro o sujeito aponta para determinados posicionamentos afetivos que não são totalmente controlados e objetivados em função dos lugares de falas dos indivíduos. Ao contrário, os lugares de fala ocupados pelo autor de literatura, ou pelos artistas de um modo geral, são lugares privilegiados de enunciação com um caráter expressamente subjetivo. Ora, ao contrário do cientista, por exemplo, ao autor de literatura é permitido criar, amoldar a realidade, carregar nas suas tintas ou simplesmente expressar os conteúdos do seu inconsciente que de alguma forma se apresentam ao Ego como estruturas "racionais" durante o processo de escrita. Desse modo, tem-se que o papel da subjetividade é, em certa medida, relevante para a enunciação. Para Magalhães,

sem a interferência da subjetividade, é impossível qualquer escolha entre as alternativas existentes na objetividade, que Na verdade, é o surgimento da subjetividade que instaura o ser social; e a história do gênero humano é a história da intervenção da subjetividade na objetividade. É nessa relação que se consubstancia a força do sujeito/autor (MAGALHÃES: 2003). ).

A intencionalidade do enunciador está então latente no discurso e, como pudemos ver, esta se refere diretamente a questões subjetivas e ao momento em que ocorre sua construção. Logo, se nos referimos à determinação do sujeito sobre os discursos escolhidos temos que toda objetivação discursiva possui um ponto de vista autoral. Retornando a Pêcheux temos na questão das escolhas do sujeito sobre o discurso na noção de esquecimento. Esta noção se refere ao efeito de ocultação parcial que indica "tudo o que teria sido possível ao sujeito dizer" (mas que não diz) ou o campo de "tudo a que se opõe o que o sujeito disse". A instância que rejeita ou aceita determinado discurso seria a consciência que se percebe como "possuidora" total do enunciado. Para o autor o indivíduo, por meio do esquecimento, seleciona caminhos para tornar o seu discurso inteligível. Tal premissa pressupõe que o sujeito consciente atua sobre o seu discurso segundo a lógica do seu local de fala.

Aqui esse autor pode ser interpretado, mantidas todas as outras diferenças, no mesmo lugar de Lukács, quando se refere à capacidade ontológica do ser social de criação do novo. Haverá sempre a possibilidade do desvio, do equívoco, isto é, da possibilidade de superação da identificação. Nesse sentido, o sujeito, determinado social e condicionado pelo inconsciente, tem sempre um lugar de nãofiliação, dado também pelas possibilidades da própria objetividade, seja ela tomada no nível macro, ou 
referido, como faz Pêcheux, à língua quando esta incorpora a poesia (MAGALHÃES, 2003). ).

O autor é assim invisível na medida em que por trás do assujeitamento existe uma estrutura psicológica que, em última instância, decide sobre o que deve ser dito. Porém, cabe aqui ponderarmos se esta subjetividade é efetiva ou apenas relativa. Se o inconsciente e fatores externos atuam sobre o sujeito, o Ego cria, por meio das escolhas que permite realizar, apenas uma sensação de controle. Ou seja, independentemente de suas escolhas, a autoria seria em sua essência apenas mais uma instância do jogo de luzes e sombras no qual inconsciente e consciente, o Ego e o Outro ora aparecem, ora desaparecem para organizarem discursos.

\section{Considerações finais}

Vimos no decorrer deste artigo que o autor não é um conceito fácil de ser delimitado, exigindo uma concepção discursiva de autoria e a noção de que este conceito está sujeito ao contexto-sócio histórico, às condições de produção e mesmo aos conceitos de estilo e leitor.

Diante destes diferentes fatores e se transpusermos a discussão do autor para o texto temos que não há transparência nos textos (POSSENTIa), mas sim construções de sentidos realizadas ininterruptamente pelos agentes envolvidos no processo de enunciação e recepção do enunciado.

Assim, temos que:

i) uma teoria da leitura não pode restringir-se ao leitor; ii) uma teoria da leitura que envolva mais de um ingrediente, por exemplo, o leitor e o texto, ou o leitor, o texto e o autor, deverá, como condição mínima, encarar todos os ingredientes a partir do mesmo ponto de vista (...) Será equivocado e pouco produtivo encarar o leitor de um ponto de vista discursivo e o texto de um ponto de vista estrutural. Ou encarar o leitor de um ponto de vista histórico e negar esta propriedade ao texto. Ou considerar as condições de leitura sem considerar as condições de produção (POSSENTI, 1999).

Assim, ainda que a questão da autoria permaneça em aberto, temos que a análise de obras literárias deve levar em consideração o leitor, e o arcabouço que este possui antecipadamente à leitura; o texto e a materialidade da obra em si, assim como seus aspectos lingüísticos; e o autor, não esquecendo as relações de síntese operadas pelo Ego entre o Outro e o outro. Ressaltamos que o autor representa para o leitor parte do outro que lhe é exterior, desse modo, a leitura é também síntese. O que queremos enfatizar é a impossibilidade de analisarmos qualquer texto unilateralmente e da importância de compreendermos o processo de produção e leitura como fluxo e não como instâncias estanques e incomunicáveis, pois este fluxo faz parte do processo de construção dos sujeitos e pertence à história.

\section{Bibliografia:}

ALTHUSSER, Louis. Aparelhos Ideológicos de Estado - Nota sobre os Aparelhos Ideológicos de Estado. Rio de Janeiro: Graal, 1985.

. A querela do humanismo.

. Freud e Lacan, Marx e Freud. 4a ed. Rio de Janeiro: Graal: 2000.

ACHARD, Pierre et al. O papel da memória. Campinas: Pontes, 1999. 
AUTHIER-REVUZ, Jaqueline. Palavras incertas: as não-coincidências do dizer. Campinas: Unicamp, 1998. . Heterogeneidade(s) enunciativa(s). Cadernos de Estudos lingüísticos, Campinas, n. 19, 1990.

BARROS, Diana Luz Pessoa. Contribuição de Bakhtin às teorias do discurso. In: BRAIT, Beht (Org.). Bakhtin, dialogismo e construção do sentido. Campinas: Unicamp, 1997.

BENVENISTE, Émile. Problemas de lingüística geral I. Campinas: Pontes, 1991.

BAKHTIN, Mikhail. Questões de literatura e de estética. 3ª ed. São Paulo: Hucitec, 1993. . Marxismo e filosofia da linguagem. São Paulo: Hucitec, 1990.

CASTORIADIS, Cornelius. A instituição imaginária da sociedade. Rio de Janeiro: Paz e Terra, 2000.

DELEUZE, G. Conversações: 1972-1990. Rio de Janeiro: 34, 1992.

FISCHER, Rosa Maria Bueno. Foucault e a análise do discurso em educação. Cad. Pesqui, novembro de 2001, n.114, p. 197-223.

FREUD, S. O Ego e o Id. ESB Vol. XIX. Rio de Janeiro: Imago, 1976.

FROMM, Erich. Conceito marxista do homem. 3ª ed. Rio de Janeiro: Zahar, 1964.

FOUCAULT, M. A ordem do discurso. 5ª ed. São Paulo: Loyola, 1999.

. Arqueologia do saber. Petrópolis: Vozes, 1972.

O que é um autor? Lisboa: Passagens, 1969.

. A arqueologia do saber. Rio de Janeiro: Forense, 1986.

. As palavras e as coisas. Lisboa: Portugália, [s.d.].

. O que é um autor? Lisboa: Vega/Passagens, 1992a.

. Vigiar e punir. Petrópolis: Vozes, 1987.

FURLANETTO, Maria Marta. "Sujeito epistêmico e materialidade do discurso: o efeito de singularidade". Revista Linguagem em (Dis)curso, volume 3, número especial, 2003.

JACOBI, J. Complexo, arquétipo e símbolo na psicologia de C. G. Jung. São Paulo: Cultrix, 1995.

LACAN, Jacques (1964). O Seminário, livro XI: Os quatro conceitos fundamentais da Psicanálise. Rio de Janeiro: Zahar, 1985.

LUKÁCS, George. O trabalho. Tradução Ivo Tonet. Maceió: 1997, mimeo.

. A reprodução. Tradução Sérgio Lessa. Maceió: 1992. mimeo. 
. Os princípios ontológicos fundamentais de Marx. São Paulo: Ciências

Humanas, 1979.

. Existencialismo ou marxismo? São Paulo: Ciências Humanas, 1979.

MAGALHÃES, Belmira. “Análise do discurso e práxis social/política”. Revista Linguagem em (Dis)curso, volume 3, número especial, 2003.

OLIVEIRA, Augusto Cesar Freitas. Razões “humanas” para esquecer Louis Althusser.

ORLANDI, Eni. Interpretação. Petrópolis: Vozes, 1996.

PÊCHEUX, Michel. “Análise automática do discurso” (AAD-69). In: GADET, F.; HAK, T. (orgs.). Por uma análise automática do discurso: uma introdução à obra de Michel Pêcheux. Campinas: Unicamp, 1993.

. Semântica e discurso: uma crítica à afirmação do óbvio. Campinas: Unicamp, 1988.

. O discurso: estrutura ou acontecimento. São Paulo

\section{Notas:}

(1) Antes de prosseguirmos e já que mencionamos Foucault cabe lembrar que a Análise do Discurso Francesa (ADF) articula estruturalismo - do qual ele é porta voz por muito tempo -, teoria da ideologia e psicanálise (leia-se psicanálise lacaniana). É esta junção tripla que determina a posição do sujeito nesta corrente teórico-metodológica. Nela o sujeito é porta-voz dos discursos do outro, sendo em certa medida dominado por este discurso, ao qual está inexoravelmente preso (POSSENTI, 1995).

(2) Foucault afirma ainda que: "A escrita se identifica com a própria exterioridade desdobrada" (FOUCAULT, 1969: 268).

(3) Em Althusser temos: "Marx rechaçava a idéia de que se pudesse encontrar no homem, como sujeito de suas necessidades, não só a explicação última na sociedade, mas" também isso é fundamental, a explicação do homem como sujeito" (ALTHUSSER, 2000: 84).

(4) Cabe aqui mencionarmos a noção bakhtiniana de polifonia. Bakhtin percebe que outras vozes, que não a do sujeito, condicionam seu discurso. Desse modo, não há signos neutros, já que eles são afetados pelo contexto histórico e social no qual os falantes se inserem.

\section{Mini Currículo :}

Doutoranda em Comunicação pela Universidade Federal de Pernambuco (PPGCOM/UFPE) e mestre em Sociologia pela Universidade Federal de Pernambuco (PPGS/UFPE). E-mail: caroldanifg@gmail.com. 